\title{
Nonnative Teachers' and Observers' Evaluation of Teachers' Teaching Quality: Perceptual Convergences and Divergences in Postobservation Conferences
}

\author{
Amirhamid Forough Ameri (i) \\ Department of English Language and Literature, Allameh Tabataba'i University, Tehran, Iran \\ Correspondence should be addressed to Amirhamid Forough Ameri; ahfameri@gmail.com
}

Received 25 December 2021; Accepted 17 January 2022; Published 29 January 2022

Academic Editor: Xiao-Guang Yue

Copyright (c) 2022 Amirhamid Forough Ameri. This is an open access article distributed under the Creative Commons Attribution License, which permits unrestricted use, distribution, and reproduction in any medium, provided the original work is properly cited.

\begin{abstract}
One of the major purposes of observation is the improvement of instruction. In fact, observers evaluate teachers' teaching quality and negotiate their critical comments with teachers in postobservation conferences. This paper was an attempt to investigate and compare Iranian EFL teachers' and observers' evaluations of teachers' teaching quality. Specifically, we attempted to figure out any possible perceptual matches and/or mismatches between teachers and observers concerning teachers' teaching quality. To this end, postobservation conferences between three Iranian EFL observers (one female and two male) and 11 Iranian EFL teachers who worked at a language institute in Iran were audio-recorded, transcribed, and analyzed. Our findings indicated that two major themes were recurrent vis-à-vis observers' evaluations; that is, their evaluations were mainly based on the specific teaching methodology of the institute as well as teachers' and learners' pronunciation and intonation. Three perceptual matches were found: teachers' agreement with the observers' comments regarding teaching methodology, pronunciation and stress patterns, as well as teachers' general information. Furthermore, three major perceptual mismatches were found when teachers disagreed with the observers' comments regarding teaching methodology, pronunciation and stress patterns, and teachers' time management. Finally, our findings indicated that most of such perceptual mismatches were resolved through the dialogic interaction that occurred between the observers and teachers. A practical implication is that holding such postobservation conferences is of utmost importance as they might be mutually beneficial for both observers and teachers.
\end{abstract}

\section{Introduction}

Teaching, learning, and supervision are interrelated, but "what is of interest is how they are related and what the ramifications of that relationship might be for supervisors" ([1], p. 321). Perhaps one of the best definitions of supervision is provided by Weller as "the improvement of instruction," and the majority of attempts to define supervision have had their focus on teachers' behavior; relatively few have focused on students' behaviors; and "fewer still concerned themselves with the learning environment or opportunities for engagement by the student" (as cited in [1], p. 321). Conventionally, teachers' teaching quality has been investigated using two separate, but related, processes: "administrative evaluation and instructional supervision" ([2], p. 229).
Robinson and Campbell [3] pointed out three purposes for teacher evaluation: first, "it serves a performativity ideology, whereby public-sector services, including schooling, are required to develop greater accountability to their stakeholders" (p. 674), including students, parents, taxpayers, and policymakers. Second, teacher evaluation provides solid evidence to make decisions about teachers' promotion and career development. Third, school effectiveness can be assessed through teacher evaluation. In fact, teachers are seen as a part of the wider contexts of schools and institutes.

Wang et al. [4] maintained that in the current literature, "teaching quality is neither a widely agreed upon nor uniformly accepted concept" (p. 331). Instead, it is based on various assumptions and is defined differently. In fact, 
teacher evaluation scholars have made a distinction between teacher quality and teacher practice. Teacher practice is viewed as "an empirical or descriptive concept referring to all the work of teachers, both inside and outside the classroom," whereas, teacher quality is "a normative concept ... concerned with what is thought, by evaluators, to be good practice" ([3], p. 674). Kennedy ([5], p. 60) categorized teacher qualities into three groups: those that teachers already possess before starting to teach, which are called "personal resources"; those that teachers engage in doing in their everyday teaching practices called "performance"-what teachers do in their practice [6]; and those related to teachers' influence on their students and the way they can inspire them to get higher grades, which are called "effectiveness." Pajak and Arrington ([2], p. 228) stated that there is an agreement among researchers, policymakers, and educational practitioners that "the single most important factor contributing to student learning is the quality of teaching" (e.g., [7]). There are other scholars who believe that the nature of quality and ways of measuring it is a controversial issue (e.g., [8]).

To the best knowledge of the current researchers, no study in the literature has been conducted to investigate and compare teachers' and observers' evaluations of teachers' quality of teaching in postobservation conferences taking place immediately after the teachers have been observed, which is the purpose of this study.

\section{Literature Review}

As Ingvarson and Rowe [9] put it, although some findings from recent research studies highlight the significance of teaching quality in enhancing learners' academic performances, some methodological issues regarding the evaluation of teacher quality are not fully understood. According to Marzano and Toth [10], "More rigorous and comprehensive feedback to teachers is one of the hallmarks of current efforts to reform teacher evaluation. Teacher observation is a very direct way to provide feedback" (p. 41). As Pajak [11] put it, class observation and feedback have formed important parts of clinical supervision of both preservice teaching and inservice training for several years. Harris believes that supervision is "one of five major functions for the operation of good schools. The other functions are general administration, teaching, management, and special service functions" (as cited in [12], p. 303).

Giving and receiving feedback on teachers' performance in class is one of the characteristics of professional training. This feedback might be in two ways: (a) a written report and/ or (b) a postobservation conference with the observer [13]. In ref. [14], Waite noted that:

Much, though, certainly not all, of the work of supervisors is carried out in face-to-face interactions with teachers, administrators, and others. The prevalent medium or channel for these encounters is talk. Supervisory conferences, especially pre- and postobservation conferences, have attracted the attention of researchers primarily because they are occasions for such face-to-face interaction with the ostensible purpose of improving instruction (p. 349).
According to Henard [15], "whatever the support provided to the quality of teaching (program evaluation, professional development, etc.), all the institutions have implemented evaluation instruments in order to closely monitor their action in that field" (p. 82). Many trainers and observers make use of observation instruments to provide teachers and trainees with a written report. Drawing on the work by Kennedy [16], Caughlan and Jiang [17] summarized the assumptions underlying the creation and utilization of observation instruments as follows: "That competent performance is self-evident, that decisions can be inferred from action, that visitors understand situations, and that practitioners and observers will agree upon a limited range of appropriate responses to situations" (p. 376). Furthermore, Hill et al. [18] noted that there is an obvious need for better measures of this construct and more information is required about whether those measures are valid or not.

Malderez [19] put forward four purposes for observation: "for professional development, for training, for evaluation, and for research" (p. 179). In observation for professional development, the teacher observed has the right to decide whether and/or how to make use of the information provided by the observer's observation. In observation for training, "the focus of learning is on skilled practitioner behavior," which is often used in preservice training ([19], p. 180). Making a judgment is the focus in observation for evaluation in which decisions might be made about whether teachers can pass some courses. As Sheal [20] argued, the majority of observation is performed for teacherevaluation purposes, resulting in teachers typically considering observation as a menace. However, Vásquez ([21], p. 35) mentioned that the purpose of observation is no longer just evaluative, and today promoting "teachers' reflection and their ongoing professional development" is also the focus of observations. Finally, in observation for research, "the focus is initially on generating descriptions and plausible explanations of educational phenomena" ([19], p. 181).

Postobservation conferences normally focus on the teacher's behavior rather than on improving the teacher's skills. Since feedback from observers is usually "subjective, impressionist, and evaluative, teachers tend to react in defensive ways, and given this atmosphere, even useful feedback is often 'not heard' ([20], p. 93). Waite [22] distinguished three types of teachers' roles that took place in postobservation conferences: passive, collaborative, and adversarial. He noted that teachers did not exclusively take on one of these roles all through the conferences but showed features of each of these roles at different times during conferences. According to Yurekli [23], postobservation conferences are feedback meetings that lead to a variety of intervention types such as “'guiding', 'advising', 'suggesting', 'recommending', 'criticizing', 'challenging', 'questioning', 'facilitating', 'helping', 'nurturing', or 'judging”’ (p. 304).

Waite [22] also distinguished three types of dynamic phases in postobservation conferences: "(a) the supervisor report phase; (b) the teacher response phase; and (c) a programmatic phase" (p. 33). In the first phase, the supervisor takes the floor and talks about the topics noted during the observation time. During this phase, supervisors 
have the longest turns, whereas teachers' turns tend to be limited to acknowledgments such as "um hum." In the second phase, teacher response phase, "teachers have longer turns and the supervisor assumes an acknowledging posture," and as teachers normally "have and can keep the floor in this phase, they may advance their own agenda as well as their rationale for observed teaching behaviors" ([22], p. 34). In the last phase, the programmatic phase, teachers tend to be the initiators of topics to be discussed with supervisors. In fact, in this last phase, the turns are equally distributed between teachers and supervisors.

\subsection{Research on Postobservation Feedback and Teaching} Quality. In recent years, researchers have become increasingly interested in studying a variety of issues with regard to the postobservation feedback. Furthermore, in the literature, researchers have studied the concept of teaching quality extensively. In this section, we are going to review some lines of research concerning the notions of postobservation feedback and teaching quality.

One of the issues which has been studied with regard to the postobservation feedback is reflective thinking. Kim and Silver [24] conducted a microanalysis of postobservation conversations between classroom teachers and mentors. They used a conversation analysis approach and indicated "how the sequential organization of an episode (i.e., who initiates the interaction, question format used by mentors) could potentially serve to provoke or hinder teacher reflection" (p. 203). Six teachers and two mentors were the participants in this study which was carried out in Singapore. Kim and Silver [24] concluded that, if a dialogic approach is adopted and followed by teachers and mentors, postobservation professional conversations can be fruitful settings for reflective thinking.

Copland [25] investigated causes of tension in postobservation feedback in preservice teacher training. Four trainers and nine trainees from one British institution participated in this research in which feedback was the main focus of study. In this study, Copland [25] intended to "show how the participation structures and the discourse practices they engendered created tension in feedback" (p. 467) by collecting field notes and by audio and video recording the feedback sessions. She concluded that, whereas many scholars believed that this tension is caused by "incompatibility of the assessment and development roles that the trainer must perform," her research indicated that tension might have its roots in a discrepancy in expectation among trainers and trainees regarding the aim and performance of feedback ([25], p. 466).

In 2011, also on an initial teacher training program, Copland conducted a linguistic ethnographic analysis on negotiating face in feedback conferences. The participants were four trainers and nine trainees. She concluded that "feedback conferences conform to generic conventions, within which a degree of face threatening talk, such as negative evaluation is acceptable" ([26], p. 3842).

Vásquez [21] carried out the discourse analysis of postobservation meetings. She analyzed six transcripts of postobservation meetings from one semester in a small university Intensive English Program in the southwestern United States. In her study, different politeness strategies used by observers in the delivery of suggestions and advice to teaching assistants were found. She concluded that "A characterization of the postobservation meeting as a 'globally face-threatening' activity is supported by participants' commentary in questionnaires and interviews" (p. 33).

Using ethnographic methods and conversation analysis, Waite [27] investigated five teacher-supervisor conferences. The supervisors and teachers who took part in this study were participants in a graduate program for beginning teachers at a university in the northwestern United States. Nonparticipant and participant observations were utilized to collect the data. Waite [27] distinguished three roles that teachers might adopt in postobservation meetings: passive, collaborative, and adversarial. He elaborated on how these roles were constructed moment-by-moment and face-toface. He described passive role as correlating with "a relatively strong supervisory agenda," in which the teacher "accepts both the supervisor's authority and suggestions, attempting to align his teaching with the supervisor's beliefs" (p. 681). The collaborative conference role was shown to correlate with a much weaker supervisory agenda, permitting teachers adopting this role to decide whether to respond to any of the supervisor's recommendations or not, and if so, how to do that. However, "When both teacher and supervisor bring strong agendas to the conference and the teacher does not capitulate, the teacher may enact the adversarial conference role" ([27], p. 682).

The quality of teaching has also received considerable attention in the literature. For instance, Kotirde and Yunos [28] investigated the supervisor's role to improve the quality of teaching in Nigeria secondary schools. In fact, they made a review on some issues with regard to supervision in Nigerian context. The findings of their study indicated that "supervisors as catalysts should facilitate the implementation of the various sets of roles which will improve the teachinglearning situation" ([28], p. 53). They concluded that poor supervision of schools was one of the problems of the secondary school system in Nigeria, with other problems being inadequate funding, inadequate facilities, low morale of staff, and frequent changes in policies ([28], p. 58).

Leigh and Ryan ([29], p. 141) investigated how and why teacher quality had changed in Australia. They used "consistent data on the academic aptitude of new teachers," and compared those who had entered the teaching profession in Australia over the past two decades. They found that the aptitude of new teachers had fallen considerably for two reasons: "A fall in average teacher pay (relative to other occupations) and a rise in pay differentials in nonteaching occupations" ([29], p. 141).

Therefore, as noted in this section, such notions as reflective thinking, tension, negotiating face, as well as the discourse and conversation analysis of postobservation meetings have been the focus of some studies in the literature. Moreover, the supervisors' role to improve the quality of teaching and the causes of change in teaching quality as 
well as the ways through which the changes had occurred have been investigated by other researchers. However, there are still some controversial issues which need to be attended to by researchers. One of such issues is how teachers and observers evaluate teachers' teaching quality in postobservation conferences. Another controversial issue is to explore teachers' and observers' perceptual matches and/or mismatches concerning teachers' teaching quality in postobservation conferences.

\section{Purpose of the Study}

This paper aims to investigate and compare Iranian EFL teachers' and observers' evaluations of teachers' teaching quality. In fact, in this study, we attempted to figure out any possible perceptual matches and/or mismatches concerning teachers' teaching quality through the dialogic interaction taking place between teachers and observers immediately after the teachers were observed. Specifically, it seeks to find answers to the following research questions:

(1) How do Iranian EFL teachers and observers evaluate teachers' teaching quality in postobservation conferences?

(2) What are Iranian EFL teachers' and observers' perceptual matches and/or mismatches concerning teachers' teaching quality in postobservation conferences?

\section{Method}

Smyth and Henry ([30], p. 47) presented an alternative model of supervision called clinical supervision, a "supervisory strategy" that consisted of four phases: (1) preobservation conference, (2) observation, (3) analysis, and (4) postobservation conference. The current study includes all phases of this model except the preobservation conference phase, which is not done at the language institute where this study was carried out.

4.1. Setting and Participants. The participants of this study were three Iranian EFL observers (one female and two males) and 11 Iranian EFL teachers who worked at the Adult Departments of a language institute in Kerman, Iran. This language institute is affiliated with the Ministry of Education. It is one of the well-established language institutes where people, especially school students, attend English classes mainly to prepare for the national university entrance exam or international exams such as TOEFL or IELTS. All the classes meet two sessions per week for 21 sessions during a season, with each session lasting for one hour and fortyfive minutes. All learners' first language is Persian. At this institute, general English proficiency is taught through six stages: Basic, Elementary, Preintermediate, Intermediate, High-Intermediate, and Advanced. Each stage is then divided into three levels. Therefore, there are 18 levels from Basic 1 to Advanced 3. Students should pass each level by getting at least 60 on the final exam and 75 in total (the Final Grade consists of $60 \%$ students' class activity and $40 \%$ their final exam score) to be qualified to attend the next higher level. In all levels, teachers are required to follow the established teaching methodology of the institute step by step. While observing teachers, the observers mainly evaluate teachers' quality of teaching based on whether and how well they have followed the teaching methodology.

For the purpose of this study, three observers were selected based on convenience sampling, that is, those three (out of four observers) who were present in the summer term in which this study was conducted. All three observers consented to participate in this study. To keep these three observers' identity confidential, we will call them as $\mathrm{A}, \mathrm{B}$, and $\mathrm{C}$ in this paper. Of the three observers, only one of them, observer A, had the experience of living in a foreign country. Observers' mean year of teaching experience was 24, and their mean year of observing experience was over 11 (see Table 1). In the summer term in which the data were collected, the three observers taught different levels; they also observed several teachers' classes (see Table 2).

The eleven teachers were also chosen based on convenience sampling. They were selected from among those teachers who were on the three selected observers' lists of observation in the summer term. Furthermore, out of those teachers who were on the observers' lists of observation, only the ones whose class periods did not interfere with those of the researcher were selected. Teachers' mean year of teaching experience was 13, and none of them had lived in a foreign country (see Table 3). In order to maintain teachers' identities confidential, we will refer to them as Teacher 1, 2, etc., in this study.

All teachers worked full time in the summer term; that is, they held at least six classes; they worked an average of 24 hours a week. At this institute, teachers should teach each level once or twice to get a raise to the next level. In fact, observers observe teachers' classes regularly each term to evaluate their quality of teaching and to make decisions as to whether teachers may be offered promotion to the next level. Therefore, observers usually visit the highest level that a teacher can teach. In this study, five out of the 11 teachers (teachers 2, 3, 4, 7, and 11) taught the highest level they could teach in the summer term, and that highest level was observed by the observers. It is worth noting that teachers usually try their best, especially when they are observed, to gain promotion to a higher level, which, in turn, leads to an increase in their fee.

4.2. Instruments. The class observation form of the institute was used as the instrument in this study to collect the data regarding teachers' and observers' evaluations of teachers' teaching quality. This observation form is made up of the following sections: (a) the steps that should be followed by teachers while teaching at different levels according to the teaching methodology, (b) teachers' professional qualities, (c) teachers' personal qualities, (d) students' behavior and attitude, (e) observer's overall recommendations for the teachers' better performance, and (f) teachers' comments. At the end of each section, some space is provided for the 
TABLE 1: Observers' background information.

\begin{tabular}{lccccc}
\hline Observer & Gender & Education & $\begin{array}{c}\text { Years of teaching } \\
\text { experience }\end{array}$ & $\begin{array}{c}\text { Years of observing } \\
\text { experience }\end{array}$ & $\begin{array}{c}\text { Residence in an English } \\
\text { speaking country }\end{array}$ \\
\hline A & Female & B.A. (TEFL) & 26 & 15 & Yes (10 years) \\
B & Male & M.A. (TEFL) & 21 & 11 & 8 \\
C & Male & M.A. (TEFL) & 25 & 8 & \\
\hline
\end{tabular}

TABLe 2: Statistical information about observers' classes and postobservation conferences.

\begin{tabular}{lccc}
\hline Observer & Number of classes taught & Number of classes observed & Number of postobservation conferences recorded \\
\hline A & 3 & 14 & 2 \\
B & 6 & 14 & 2 \\
C & 5 & 9 & 7 \\
Total & 14 & 37 & 11 \\
\hline
\end{tabular}

TABLE 3: Teachers' background information.

\begin{tabular}{|c|c|c|c|c|}
\hline Teacher & Gender & Education & Years of teaching experience & Level observed \\
\hline 1 & Female & B.A. (TEFL) & 17 & Preintermediate 1 \\
\hline 2 & Male & M.A. (Translation) & 7 & Preintermediate 1 \\
\hline 3 & Female & M.A. (TEFL) & 9 & Preintermediate 3 \\
\hline 4 & Female & M.A. (TEFL) & 17 & High-intermediate 3 \\
\hline 5 & Female & B.A. (TEFL) & 14 & Interintermediate 2 \\
\hline 6 & Female & M.A. (TEFL) & 18 & Interintermediate 3 \\
\hline 7 & Female & M.A. (English Literature) & 2 & Basic 2 \\
\hline 8 & Female & M.A. (Anthropology) & 25 & Elementary 2 \\
\hline 9 & Female & M.A. (TEFL) & 20 & Preintermediate 2 \\
\hline 10 & Male & B.A. (English Literature) & 7 & Interintermediate 3 \\
\hline 11 & Male & M.A. (TEFL) & 7 & High-intermediate 3 \\
\hline
\end{tabular}

observers' comments about the teachers' performance regarding the items included in each section.

4.3. Data Collection Procedure. At this institute, observations and postobservation conferences normally occur once per class during each term. Such observations are typically carried out by the observers to figure out what happens in each class, and, to evaluate teachers' teaching quality, and to provide some guidance and support for their further educational improvement. Three observers observed teachers' classes during which observers filled out the observation form by putting a check mark in front of the items which had been done correctly or writing short comments such as "done well" or "not good." Then, at the end of each section, the observers wrote down their comments about the teachers' performance regarding the items included in that section. In addition, at the end of the class, the observers added their final overall comments about teachers' whole performance. Next, there was a postobservation conference between teachers and observers, during which teachers and observers evaluated teachers' performance by engaging in discussing their points of view on teachers' teaching quality in that session based on the observation form. In fact, teachers and observers discussed both specific issues that had taken place in the class and some general issues regarding teachers' teaching quality in the class. These postobservation dialogic interactions were recorded and later transcribed by the researcher to find any possible perceptual matches and/or mismatches concerning teachers' teaching quality.

At the beginning of the summer term, before they started observing classes, the three observers were fully informed about the purpose of this study and they had given their consent to the recording of the postobservation conferences. However, as the teachers were observed without notice, the researcher was not permitted to talk with the observers before their classes started. Therefore, at the end of each observation, the researcher entered the teachers' classes, and explained the purpose of this study to the teachers and briefed them on what they were expected to do as participants of the current study, namely, engaging in dialogic interaction with the observers in order to evaluate their teaching quality. The researcher also explained that the postobservation conferences were not going to be carried out in the form of monologues on the part of observers, with the teachers just listening to the observers' comments, but that the teachers were expected to respond to the observers' comments. All eleven teachers consented to participate in this study.

4.4. Data Analysis Procedure. The collected data in this study consisted of 11 audiotaped postobservation conferences (around 30\% of all postobservation conferences carried out during the summer term), ranging in length from about five to 15 minutes. Qualitative data analysis procedures were utilized to analyze the ways in which teachers and observers 
evaluated teachers' teaching quality and to find any perceptual patterns indicating teachers' and observers' matches and/or mismatches in this regard.

In order to analyze the data, the audiotapes of postobservation conferences were transcribed using Microsoft Word. After this stage, the transcripts were perused by the researchers a couple of times to find the recurrent themes. Based on the purposes of this study, different sections of the transcripts were highlighted with four different colors to indicate observers' evaluations, teachers' evaluations, perceptual matches, and mismatches. Then the researchers embarked on examining, comparing, contrasting, and classifying the data to gain the broad categories and themes.

Some ethical issues were taken into consideration while conducting this study. All participants including both observers and teachers were fully informed about the purpose of the study and the fact that they could withdraw from the study at any time. Furthermore, they were reassured that all the information collected via recording the postobservation conferences would be kept confidential and private. They were also assured that their identities would not be disclosed and alphabetical letters and cardinal numbers would be used to code and later refer to observers and teachers, respectively.

\section{Results}

In this section, we will present the main findings of the current study in terms of our two research questions. The results indicated that, in all postobservation conferences, observers were the initiators and teachers took a responsive role. Observers $\mathrm{A}$ and $\mathrm{C}$ initiated the meetings by presenting their own evaluations of the teachers' teaching quality in that session, whereas Observer B began by asking teachers to evaluate their own classes first and then went on to his own evaluation of their classes. Generally speaking, observers' evaluations formed the major part of the postobservation conferences, with the teachers commenting on the points raised by observers sporadically or answering their questions. In fact, in most cases, teachers took a passive role.

5.1. Research Question 1. Our first research question sought to find out how Iranian EFL teachers and observers evaluated teachers' teaching quality. The results of this study indicated that two major themes recurred throughout the dataset; that is, observers evaluated teachers' quality of teaching mainly based on the teaching methodology of the institute and teachers' and learners' pronunciation and intonation. In fact, observers' evaluations focused mainly on the established teaching methodology that all teachers are required to follow systematically. They chiefly focused on the first section of the class observation form in their evaluations of the teachers' teaching quality. As noted earlier, the first section of the observation form is related to the steps that should be followed by teachers while teaching at different levels. Overall, observers held positive views towards the way teachers had taught. They expressed their satisfaction by such complimentary remarks as the following: "You taught the grammar very well" (Observer A to Teacher 1); "your job on dialog was very good" (Observer B to Teacher 3); and "grammar was well done" (Observer C to Teacher 5). There were, however, some criticisms made by observers and perceptual mismatches between observers and teachers regarding teaching methodology, to which we are going to refer in the following section (Research Question 2).

Regarding pronunciation and intonation, observers drew teachers' attention to their own mispronunciations as well as those of their students. In some cases, observers reminded teachers of the students' mispronunciations that had not been noticed or corrected by teachers (e.g., Observer B to Teacher 3). In other cases, observers pointed out the mispronunciations that they said the teachers had made while teaching (e.g., Observer $\mathrm{C}$ to Teacher 4). However, in still other cases, observers praised teachers for their good pronunciations and fluency (e.g., Observer C to Teacher 8).

Some other minor issues were also pointed out by observers, though less frequently than teaching methodology and pronunciation. They advised teachers to manage their class time in a more efficient way so that they would not have extra time at the end of the class (e.g., Observer B to Teacher 11). They also asked teachers to strongly discourage the students' use of Farsi (teachers' and students' first language) in class (e.g., Observer $\mathrm{C}$ to Teacher 5). Furthermore, Observer $\mathrm{C}$ noted issues such as the quality of teachers' voice, the negative effect of students' mispronunciations on teachers' own pronunciation, the use of rapport building techniques by teachers to make good relationships with their students (e.g., good warm-ups at the beginning of the class), the correct word usage on the part of teachers, and teachers involving the students in class activities.

Teachers also referred to some issues that they thought had influenced their teaching quality. For instance, Teacher 3 believed that such bad classroom conditions as the malfunctioning of the air conditioner and bad quality of DVD player speakers had affected the teaching quality in her class. Teacher 9, in response to Observer C's criticism of her low voice, while teaching, referred to the low number of students in her class and her students "sharpness" as two reasons why she had not spoken louder in class. Finally, Teacher 11 teaching at a high-intermediate level, in answer to Observer B's question seeking his idea about "having a pure grammar course in an institute," referred to the fact that the sole teaching of "components of grammar, vocabulary and pronunciation" rather than language skills might have deleterious effects on the quality of teaching as well as students' learning.

5.2. Research Question 2. Our second research question sought to find out what Iranian EFL teachers' and observers' perceptual matches and/or mismatches were concerning teachers' teaching quality. Based on the analysis of the data, a number of perceptual matches and mismatches were identified which we will report in this section. 
5.2.1. Perceptual Matches: Teaching Methodology, Pronunciation and Stress Patterns, and Teachers' General Information. Perceptual matches were found between the observers and teachers in regard to teachers' teaching quality when some teachers agreed with the observers' comments regarding their performance in that session. Such perceptual matches were found concerning the following issues: teaching methodology (e.g., Observer C-Teacher 4), pronunciation and stress patterns (Observer C-Teacher 5), teachers' general information (Observer A-Teacher 2). Teachers expressed their agreement in different ways. Some only used discourse markers such as yeah, aha, ok, yes, etc., without giving any other comments; others made a response to observers' comments signaling they had the same idea as the observer or they accepted the observer's criticism; still others used both discourse markers and responses.

5.2.2. Perceptual Mismatches: Teaching Methodology, Pronunciation and Stress Patterns, and Teachers' Time Management. One of the major perceptual mismatches found between the observers and teachers in regard to teachers' teaching quality was that in some cases teachers disagreed with the observers' comments regarding the steps they were expected to follow in their teaching in that session. Actually, those teachers believed what the observers had mentioned were not included in the established teaching methodology of the institute that all teachers are trained to follow during the training courses before they start teaching. Nevertheless, most of such perceptual mismatches were resolved through the dialogic interaction that occurred between the observers and teachers. The following extract is one example of such a perceptual mismatch between $\mathrm{Ob}$ server $\mathrm{A}$ and Teacher 1 regarding the way the listening section had to be done at preintermediate levels:

\section{Extract 1}

Researcher: Do you have any ideas about what she [Observer A] said?

1 : No, just in methodology I think it was written that we play the CD nonstop the first time and I did it because of that.

A: That is fine nothing wrong with it. As a suggestion, since the dialogs are too long and confuse the students, so you can stop it after the first couple.

1: Yeah, check their answers.

A: Go to the second pair. Just as a suggestion.

1 : Whenever it is too long.

A: You can do it to make your job and students' job easier to understand.

Here, Teacher 1 referred to the written methodology in order to justify the way she had done the listening because she thought the observer's previous comment was not in line with the methodology. In fact, Observer A had suggested that "It would be nice since the dialog was too long, you could have stopped the tape after guest No 1; ask students then guest No 2, then No 3." As seen above, the teacher came to know that the observer had not criticized what she had done, but that it was just a recommendation for the teacher to make her teaching more effective.

The same perceptual mismatch took place between Observer $\mathrm{C}$ and Teacher 6 regarding the way the listening section had to be done at intermediate levels. Referring to the teaching methodology, Teacher 6 , like Teacher 1, tried to justify the way she had taught the listening. Moreover, there were other methodological issues raised by the same observer who had observed Teacher 6. One of these issues was about the way the vocabulary had to be dealt with:

\section{Extract 2}

C: Then. Vocab. Of course, it's not mentioned here in the syllabus. Normally before each major component like listening, you have a review of the whole vocab.

6: So we should review words before listening?

C: Well it's not a part of syllabus here but it is one of the suggestions in the syllabus, in methodology that before each major component like listening, you have a review of the whole vocab just one time one session.

6: Before dialog and reading I do it but before listening, sessions 5 and 10, I don't.

Here, Teacher 6 believed that it was not necessary to review the vocabulary of the whole unit before the listening section, which she thought was required only before the dialog and reading sections. In fact, it seems that the misunderstanding occurred due to the different perceptions of the word "major." In the methodology, it is mentioned that teachers are to review the vocabulary of the whole unit before each major component of each unit. Whereas Observer $\mathrm{C}$ believed that listening was also one of the major components, Teacher 6 thought that major components consisted of only the dialog and reading sections of each unit.

Another methodological issue put forward by Observer $\mathrm{C}$ in his postobservation conference with Teacher 6 was related to the role of the teacher when students made mistakes while communicating with each other:

\section{Extract 3}

C: And second thing. Please don't relay students' questions and answers. They should communicate.

6: Yes. But when they make mistakes!

C: There is no need for you. You can give hints, a corrected word. Not the whole statement, question, answer.

Here, whereas, Teacher 6 implies that correcting students' mistakes might be necessary while they were communicating with each other. Observer $\mathrm{C}$ believes that teacher intervention in the form of giving hints could be a better alternative to error correction by teachers. It is worth noting that exactly the same perceptual mismatch regarding teacher intervention occurred between the same observer and Teacher 8 who said, “sorry in fact I didn't want to play the role of an amplifier in class, I just wanted to correct the questions." Here, again Observer C emphasized the role of 
giving hints rather than relaying the corrected versions of questions and answers from one student to another.

Another perceptual mismatch found between the observers and teachers in regard to teachers' teaching quality was related to the teachers' time management in the class:

\section{Extract 4}

C: The thing was because your time was so pressed you would... [Not clear] and even in grammar I saw you would jump off some items
8: I didn't. I did every part.
C: Aha you did. (Laughing)
8: I did spoken drills. Which parts I jumped? (Laughing)
C: And you have written pas progressive instead of past.
8: Past progressive tense?
C: Yeah. You wrote pas.

As can be seen in this extract, Teacher 8, a fully experienced teacher, did not accept the observer's comment that she had skipped some parts while teaching grammar. However, the observer believed that the teacher had gone through a few steps rather hastily. He referred to a mistake that the teacher had made in her spelling of a word while writing on the board.

Still another perceptual mismatch found between the observers and teachers pertained to observers' evaluations of teachers' intonation and pronunciation. For instance, Teacher 11, who was teaching at a high-intermediate level, states that he had changed his intonation to make his explanations clear, but Observer $\mathrm{B}$, asserting that he knew that Teacher 11 had a good intonation, still believes that the teacher should not have changed his intonation at least at higher levels. The findings of this study indicated that, of the three observers, Observer $\mathrm{C}$ was the most meticulous about teachers' pronunciation. He commented on the way Teachers 4, 5, and 9 had pronounced words such as quite, quiet, thing, winner, etc.

\section{Discussion}

Overall, the results of this study indicated that, in all postobservation conferences, observers were the initiators and teachers took a responsive and passive role. In fact, most teachers opted to comment on the points raised by observers or just answer their questions, if any, which is the common procedure in postobservation conferences in EFL settings such as Iran. This passive role is in line with one of the three types of teachers' roles in postobservation conferences in which the teacher "accepts both the supervisor's authority and suggestions, attempting to align his teaching with the supervisor's beliefs" ([27], p. 681). Even when they were directly asked or invited to comment on their own performance, most teachers chose to be passive and accept observers' evaluations. A possible explanation for this might be that most teachers consider getting a raise to a higher level as the single most important purpose of observations. Therefore, they opted to act rather conservatively in response to observers' comments. In fact, fully experienced teachers such as teachers 6, 8, and 9, who had already gotten their raises to the highest level (i.e., Advanced 3), took more active roles in evaluating both their own performances and observers' evaluations. Another possible explanation for this finding might be that in Asian countries, such as Iran, teachers prefer to be more conservative in relationship with people in such roles as observers, supervisors, school managers, etc. Therefore, there seems to be a cultural tendency on the part of teachers to try not to criticize those in higher positions of power.

Our first research question sought to investigate how Iranian EFL teachers and observers evaluated teachers' teaching quality. Our findings indicated that two major themes were recurrent vis-à-vis observers' evaluations; that is, their evaluations were mainly based on the teaching methodology and teachers' and learners' pronunciation and intonation. This finding is by no means surprising because in EFL contexts both teaching methodology (the first section of the class observation form) and accurate pronunciation (one of the components in the Teachers' Professional Qualities section of the class observation form) are usually emphasized. In fact, strictly following the steps in the teaching methodology is required of all teachers and observers pay close attention to this in their evaluations of teachers' teaching quality. Moreover, as the teaching methodology of the institute is partially based on the audio-lingual method, in which all errors such as mispronunciations should be prevented and immediately corrected, observers (particularly Observer $\mathrm{C}$ in this study) drew teachers' attention to their accuracy of pronunciation and intonation.

As observers pointed out, in informal discussion sessions with the researchers, the reason they did not refer much to other sections and components of the class observation form was the fact that it was taken for granted that all teachers possessed such qualities as accuracy of writing, poise and bearing, creativity, etc. In fact, all teachers had gone through several stages before beginning their teaching career. These stages included a written exam, an interview, a preservice teacher training course held by supervisors and trainers as well as a demo. This might explain our general finding that, overall, observers held positive views towards the way teachers had taught in this study.

Our second research question sought to investigate what Iranian EFL teachers' and observers' perceptual matches and/or mismatches were in regard to teachers' teaching quality. Three perceptual matches were found: teachers' agreement with the observers' comments regarding teaching methodology, pronunciation and stress patterns, and teachers' general information. In fact, as Vásquez [21] concluded, "Very often, what teachers expect to receive from the postobservation conference is a balance of positive appraisal and constructive criticism" (p. 35). These perceptual matches could be indications that teachers considered observers' comments and even their critical remarks as constructive criticism. Nevertheless, as noted earlier, teachers might have taken observers' criticisms due to their natural tendency to be acquiescent when addressed by observers. Still another possible explanation might be that 
most teachers in EFL settings respect the observers as not only supervisors and teacher trainers but as fully experienced teachers. Therefore, their advice and criticisms are usually appreciated by all teachers.

Three perceptual mismatches were found when teachers disagreed with the observers' comments regarding teaching methodology, pronunciation and stress patterns, and teachers' time management. As can be seen, there were both perceptual matches and mismatches regarding the two issues of teaching methodology and pronunciation, a fact which might be due to the utmost importance placed on teaching methodology and teachers' and learners' pronunciation in EFL contexts.

The perceptual mismatches might have arisen from the postobservation conferences due to some reasons. Some were due to observers' and teachers' different interpretations of the steps teachers had to follow in their teaching. Such mismatches occurred mainly owing to the misinterpretation of those steps on the part of teachers and/or observers. For instance, in some cases, teachers had skipped some optional steps, which was deemed necessary by observers and vice versa. This might be due to the fact that those steps are not clearly explained as either optional or obligatory in the written methodology of the institute.

Some other perceptual mismatches concerned the role of teachers when students made mistakes while communicating with each other. Whereas teachers believed that they were correcting students' mistakes in order to help them communicate more intelligibly with each other, observers seemed to have had different ideas and regarded those corrections as unnecessary interventions. In fact, this difference might originate from observers' and teachers' different attitudes towards the same methodological technique. Observers recommended more restricted teacher intervention in the form of hints and prompts; teachers seem to have tried to facilitate learners communicating with each other.

Still other perceptual mismatches were found in regard to intonation and pronunciation. In one case, the teacher claimed to have changed his intonation to put himself across while teaching some grammatical points at a high-intermediate level. However, the observer implicitly rejected that justification on the grounds that it was not necessary as the students were at a high level of proficiency. It seems that some teachers try to make their teaching more effective and appealing using different techniques, which is obviously not accepted by observers who are more obsessed with teachers carefully following the established teaching methodology. In other cases, observers criticized teachers for not correcting some of the learners' mispronunciations. Teachers referred to such reasons as not having noticed the error or choosing not to give immediate correction. Nevertheless, observers insisted on the importance of correcting the mispronunciations as they would get fossilized if left uncorrected.

However, our findings indicated that most of such perceptual mismatches were resolved through the dialogic interaction that occurred between the observers and teachers in postobservation conferences. Kim and Silver [24] also concluded that, if a dialogic approach is adopted and followed by teachers and mentors, postobservation professional conversations can be fruitful settings for reflective thinking. In some cases, teachers came to know that what seemed to them as criticism on the part of observers was, in fact, their recommendation for them to improve their teaching efficiency and quality of teaching. In other cases, having criticized teachers for a negative point vis-à-vis their teaching quality, observers, through dialogic interaction with teachers, realized that they had made a mistake or had not noticed a part of teachers' performance carefully. Therefore, it seems that both teachers and observers benefited from the postobservation conferences.

\section{Conclusion and Implications}

The aim of the present research was twofold: first, to identify how Iranian EFL teachers and observers evaluate teachers' teaching quality and second, to investigate what Iranian EFL teachers' and observers' perceptual matches and/or mismatches are concerning teachers' teaching quality. The results of this study revealed that in all postobservation conferences, observers were the initiators and teachers took a responsive and passive role. Our findings indicated that two major themes were recurrent vis-à-vis observers' evaluations; that is, their evaluations were mainly based on the teaching methodology and teachers' and learners' pronunciation and intonation. Three perceptual matches were found: teachers' agreement with the observers' comments regarding teaching methodology, pronunciation and stress patterns, and teachers' general information. Furthermore, three major perceptual mismatches were found when teachers disagreed with the observers' comments regarding teaching methodology, pronunciation and stress patterns, and teachers' time management. Finally, our findings indicated that most of such perceptual mismatches were resolved through the dialogic interaction that occurred between the observers and teachers in postobservation conferences.

Taken together, these results suggest that although most teachers took a rather passive role in postobservation conferences, the dialogic interaction that took place between observers and teachers in such meetings proved to be conducive to the resolution of most perceptual mismatches between them. A practical implication is that holding such postobservation conferences is of utmost importance as they might be mutually beneficial for both observers and teachers. Therefore, observers may not content themselves with just filling out the observation forms in their evaluations of teachers' teaching quality.

The generalizability of these results is subject to two main limitations. First, we could not gain access to observers' written notes in observation forms, which caused us to design and conduct this study only qualitatively. Other studies might be conducted with a mixed-method design to shed further light on the purposes of this study. Second, this study was conducted with a rather small sample of postobservation conferences in only one language institute. It is recommended that further research be undertaken with a larger sample size and at different educational contexts to gain a broader picture. 


\section{Data Availability}

The qualitative data used to support the findings of this study have not been made available due to confidentiality reasons. However, the author will do his best to make them available on reasonable request.

\section{Conflicts of Interest}

The authors declare that they have no conflicts of interest.

\section{References}

[1] D. Waite, "Instructional supervision from a situational perspective," Teaching and Teacher Education, vol. 8, no. 4, pp. 319-332, 1992.

[2] E. Pajak and A. Arrington, "Empowering a profession: rethinking the roles of administrative evaluation and instructional supervision in improving teacher quality," The Yearbook of the National Society for the Study of Education, vol. 103, no. 1, pp. 228-252, 2005.

[3] W. Robinson and J. Campbell, "Evaluation of teacher quality and practice," International Encyclopedia of Education, vol. 3, pp. 674-680, 2010.

[4] J. Wang, E. Lin, E. Spalding, C. L. Klecka, and S. J. Odell, "Quality teaching and teacher education," Journal of Teacher Education, vol. 62, no. 4, pp. 331-338, 2011.

[5] M. M. Kennedy, "Sorting out teacher quality," Phi Delta Kappan, vol. 90, no. 1, pp. 59-63, 2008.

[6] M. Lampert, "Learning teaching in, from, and for practice: what do we mean?" Journal of Teacher Education, vol. 61, no. 1-2, pp. 21-34, 2010.

[7] W. L. Sanders and S. P. Horn, "Research findings from the Tennessee value-added assessment system (TVAAS) database: implications for educational evaluation and research," Journal of Personnel Evaluation in Education, vol. 12, no. 3, pp. 247-256, 1998.

[8] M. M. Kennedy, "Approaches to annual performance assessment. In M. M. Kennedy, Teacher Assessment and the Quest for Teacher Quality: A Handbook," pp. 225-250, San Francisco, CA, USA, ossey-Bass, 2010.

[9] L. Ingvarson and K. Rowe, "Conceptualising and evaluating teacher quality: substantive and methodological issues," Australian Journal of Education, vol. 52, no. 1, pp. 5-35, 2008.

[10] R. J. Marzano and M. D. Toth, Teacher Evaluation that Makes a Difference: A New Model for Teacher Growth and Student Achievement, ASCD, Alexandria, VA, USA, 2013.

[11] E. Pajak, "Clinical supervision in a standards-based environment," Journal of Teacher Education, vol. 52, no. 3, pp. 233-243, 2001.

[12] R. M. Burnham, "Instructional supervision: past, present and future perspectives," Theory into Practice, vol. 15, no. 4, pp. 301-305, 1976.

[13] F. Copland, "Legitimate talk in feedback conferences," Applied Linguistics, vol. 33, no. 1, pp. 1-20, 2012.

[14] D. Waite, "Supervisor's talk: making sense of conferences from an anthropological linguistic perspective," Journal of Curriculum and Supervision, vol. 7, no. 4, pp. 349-371, 1992.

[15] F. Henard, Learning Our Lesson: Review of Quality Teaching in Higher Education, OECD, Paris, France, 2010.

[16] M. M. Kennedy, "Attribution error and the quest for teacher quality," Educational Researcher, vol. 39, no. 8, pp. 591-598, 2010.
[17] S. Caughlan and H. Jiang, "Observation and teacher quality," Journal of Teacher Education, vol. 65, no. 5, pp. 375-388, 2014.

[18] H. C. Hill, K. Umland, E. Litke, and L. R. Kapitula, "Teacher quality and quality teaching: examining the relationship of a teacher assessment to practice," American Journal of Education, vol. 118, no. 4, pp. 489-519, 2012.

[19] A. Malderez, "Observation," ELT Journal, vol. 57, no. 2, pp. 179-181, 2003.

[20] P. Sheal, "Classroom observation: training the observers," ELT Journal, vol. 43, no. 2, pp. 92-104, 1989.

[21] C. Vásquez, “"Very carefully managed”: advice and suggestions in post-observation meetings," Linguistics and Education, vol. 15, no. 1-2, pp. 33-58, 2004.

[22] D. Waite, Rethinking Instructional Supervision: Notes on its Language and Culture, The Falmer Press, London, UK, 1995.

[23] A. Yurekli, "The six-category intervention analysis: a classroom observation reference," ELT Journal, vol. 67, no. 3, pp. 302-312, 2013.

[24] Y. Kim and R. E. Silver, "Provoking reflective thinking in post observation conversations," Journal of Teacher Education, vol. 67, no. 3, pp. 203-219, 2016.

[25] F. Copland, "Causes of tension in post-observation feedback in pre-service teacher training: an alternative view," Teaching and Teacher Education, vol. 26, no. 3, pp. 466-472, 2010.

[26] F. Copland, "Negotiating face in feedback conferences: a linguistic ethnographic analysis," Journal of Pragmatics, vol. 43 , no. 15, pp. 3832-3843, 2011.

[27] D. Waite, "Teachers in conference: a qualitative study of teacher-supervisor face-to-face interactions," American Educational Research Journal, vol. 30, no. 4, pp. 675-702, 1993.

[28] I. Y. Kotirde and J. B. M. Yunos, "The supervisor's role for improving the quality of teaching and learning in Nigeria secondary school educational system," International Journal of Education and Research, vol. 2, no. 8, pp. 53-60, 2014.

[29] A. Leigh and C. Ryan, "How and why has teacher quality changed in Australia?" The Australian Economic Review, vol. 41, no. 2, pp. 141-159, 2008.

[30] W. J. Smyth and C. Henry, "Instructional Supervision Revisited: a collaborative and responsive alternative," British Journal of In-Service Education, vol. 11, no. 1, pp. 47-55, 1984. 